\title{
The Scientific Evidence That "Intent" Is Vital for Healthcare
}

\author{
Bob Johnson \\ Consultant Psychiatrist, Isle of Wight, UK (Retired) \\ Email:DrBob@TruthTrustConsent.com
}

How to cite this paper: Johnson, B. (2017) The Scientific Evidence That "Intent" Is Vital for Healthcare. Open Journal of Philosophy, 7, 422-434.

https://doi.org/10.4236/ojpp.2017.74022

Received: August 22, 2017

Accepted: September 11, 2017

Published: September 18, 2017

Copyright (C) 2017 by author and Scientific Research Publishing Inc. This work is licensed under the Creative Commons Attribution International License (CC BY 4.0).

http://creativecommons.org/licenses/by/4.0/

\begin{abstract}
THINKING cannot occur without electrons, a point philosophically, scientifically and irrefutably confirmed for all, by the Electroencephalogram (EEG). However for 100 years, electrons and their ilk have scrupulously obeyed the Uncertainty Principle. Probability rules. The way human beings reason is by concluding that if event B is seen to follow cause A, it will do so again tomorrow-electrons don't even support this today. Hume's critique of causality which Kant failed to refute, gains traction from Quantum Mechanics. Despite needing to insert the word "probably" into every human reasoning, healthcare demonstrates an element of unexpected stability. The label "intent" is expanded to cover this anomaly, endeavouring to highlight how living cells cope with the impact of this unknowability, this Uncertainty. Mental health follows suit, though here the uncertainty comes additionally from "blockage" of the frontal lobes consequent upon trauma/terror. The collapse of today's psychiatry is pathognomonic, and medically solipsistic. The role of "intent", and its close relative, consent, are offered as remedies, not only for mental disease, relabelled here "social defeat", but also for the global disease of violence, culminating in the biggest health threat of them all, thermonuclear war.
\end{abstract}

\section{Keywords}

Thermonuclear War, Quantum Uncertainty, Intent, Healthcare, Healthier Psychiatry

\section{Introduction}

UNCERTAINTY now permeates our every subatomic foundation. Philosophers think. But, whether they agree, or more commonly don't, their thinking necessarily entails shuffling electrons through cerebral tissue without which it simply cannot occur. No thought can even begin, unless electrons speed through brain 
cells-yet every one of those frantic subatomic particles is indelibly unknowable. It's not a question of who is right, or which proposition is wrong-no assertion whatsoever can possibly be made, without deploying electrons to do so. And, for the last 100 years, no single electron is remotely knowable in any sense that even approaches certainty. Probable, yes. Certain, no. Not only that, but as the verbatim excerpts included below make painfully clear, the chains of cause and effect without which logic (and indeed all reasoning) cannot proceed, do not apply to, and therefore are not supported by these, our one and only, subatomic foundation stones.

Electrons of course, power every chemical molecule, every motor, every spark plug, every enzyme and nerve impulse, to say nothing of the frontal lobes, the dire significance of which is raised later in this paper. So to assert that electrons power cognition should raise few eyebrows. Yet despite being ubiquitous, these mighty workhorses of our subatomic world are elusive to the point of farce-worse, the tighter you define them, the nearer you approach their "ultimate" nature, the more indistinct and vague they become. The harder you try, the further you fall, and the worse the result. The epitome of scientific endeavour is to strive ever more strenuously-rewards come only to those who labour unstintingly-electrons knock this firmly on the head; no wonder their fundamental nature is given short shrift. Maxwell's Law of Pure Cussedness applies to electrons and their ilk in spades-if this is the ultimate cosmic joke, it takes exceptional agility of mind to see past it.

The conventional "answer" is to refer to an electron not so much as having a precise definition or location, merely to it "being" itself a cloud, a bundle of assorted probabilities. Wrestling with these intrinsic improbabilities has assuredly powered our unbelievable electronics, but, despite all the reassurances regularly emanating from Quantum physicists and others who should know better, the electron and its ilk remain, in essence, unknowable. A proposition anyone can easily test by taking Quantum Mechanics to its logical conclusion, and thereafter inserting the word "probably" into every conceivable statement, bar none. Assuming that the world we see operates the way it does because of its subatomic building blocks, then strict science mandates we do this-at least it does, if Quantum Mechanics is properly accorded the philosophical significance that is its due. The challenge is to find an agreed, realistic, scientific, objective basis for amending "I'll probably be there for you", so that it becomes a healthier-"your peace-of-mind relies on you being certain of me".

Copious resources are lavished on researching cognition, how thinking works, what goes on when we are conscious, and so forth. But no thought exists that does not involve electrons-the aptly named electroencephalogram (EEG) demonstrates this objectively, irrefutably and for all to see-Non-Subjective Science at its purest. EEGs can demonstrate whether the person is awake or asleep, which part of the brain is active at that particular moment, what the underlying state of alertness currently is. Pity more philosophers are not more familiar. But what these remarkable machines, and their ilk show at the very least, 
is that electrons are intimately involved in all cerebral activity. If all philosophers were thus better equipped, and if there were commensurate philosophical interest among today's technicians and their funders, then they too would be forcibly confronted with the crushing anomaly-one and all electrons behave in an irretrievably "Uncertain" way, so how can Certainty of any description ever be secured?

It's like building a reinforced concrete structure in a proven earthquake zone, and then being puzzled as to why it fails. However rigid the structure, however massive and immovable are its buttresses, only flexible buildings have any hope of surviving intact, at least partially. Since Heisenberg, indeed since Planck, our reliance on the Certainties of Science has been open to question. What this paper does is to bring into this somewhat stifled arena the whole issue of healthcare. The mystery and inexplicability is thereby transferred from how electrons behave, to how anything composed entirely and exclusively of Uncertain quanta, such as ourselves, can nevertheless overcome this intrinsic Uncertainty, and build at least the semblance of stability, or, ultimately, of health and longevity.

If science is anything, it must be rigorously governed by the evidence-if the data contravenes what we expect, our expectations must change, if we are to preserve our integrity. Not only that, but however uncongenial, however "unorthodox", if the data points away from what we've always believed, it is our vital responsibility to follow it-especially if we are interested in remaining healthy. Peer reviewers for established academic journals-steeped in the conventional view (else they wouldn't be reviewing) - are thus handed an understandable dilemma, they are charged with having to distinguish healthier unorthodoxy, from its opposite. It hasn't helped that "Theories of Knowledge", or Epistemology, is often seen as the least glamorous in all the academic pantheon. Worse, if science disintegrates, must we consign ourselves to anarchy and chaos? Is there no rational, cognitive pathway by which we can resolve this collapse? This paper offers one.

\section{The Simplest Quantum Feature of Them All}

The first sign of trouble appeared in 1899. Contrary to conventional expectations, this feature is ridiculously easy to understand. Its wider implications, of course, have yet to penetrate the popular imagination, or even that of most of academe. But at heart, it is ludicrously simple-adjectives rarely applied to Quantum Mechanics. The story is told that Max Planck went for a walk in the woods with his offspring, in 1900. Planck is said to have confided to the child that his discoveries had altered the physical world forever. Which indeed they had.

Planck's discovery can be expressed in the simplest possible terms-terms which even the least initiated will find self-explanatory. We all know about the postal service. If we are expecting a parcel, we know that it needs to be dispatched, to travel towards us, then to arrive. Substitute the word "quantum" for 
"parcel" and the inexplicability is immediately obvious. Whatever else the parcel does, it does not behave like a wave. And that's the key. With a wave, you can know or calculate where a bit of it will be at any one time-you can estimate where it came from, by counting back from where it is now, using the speed at which it travelled to get here. It's the very continuity of the wave which allows us to compute, to understand, to entertain a predictive model in our heads of what is going to happen next. Some aspects of waves are invariable, they are CERTAIN-for instance, we know that a wave cannot arrive before it has set out. A wave cannot be in two places at once. If the observer is a metre from the origin, we know it will take a wave a second to arrive, if we previously knew it travelled at a metre a second. Obvious with waves-impossible with quanta.

What Planck did was to demonstrate that energy, generally thought of as continuous, was in fact particulate. It did not leave, say a hot body, continuously, but in packets, in small discrete lumps, in quanta. Continuous processes we can cope with-once something becomes particulate, or parcelled up, its origin, travel time, and arrival become problematic. We have nothing to go on. What is obvious with any parcel service applies relentlessly to parcels of subatomic matter. It complicates things that such particles are thought of as particulate one moment, and as waves the next-complicates, but does nothing to alleviate the impoverishment of our knowing about them. This is the heart of the Uncertainty Principle.

There are other features of Uncertainty, but this one is central. It applies to every single subatomic "entity" whatsoever-none can escape it. Take a radioactive atom-the timing of the release of its next quantum, we can never know-we are restricted to dreaming up a "half-life", an estimate of how long before half its radioactivity has gone. This "half-life" is a sensible, pragmatic "work around", so characteristic of humanity's ability to cope with otherwise incomprehensibles. But what we are happy to apply to inanimate objects, we are less comfortable applying to ourselves. Suppose your visit to the clinic resulted in your being advised that half your life was over-this would surely grate on your entirely understandable susceptibilities. Healthcare needs a different vocabulary, a different mind set. We are unlikely to have first hand experience of radioactive decay, at least so far-but healthcare is commonplace, and that operates in a different mode entirely.

\section{Measuring Nanometres}

Before exploring what really happens in healthcare, it is important to emphasise the philosophical impediments that Quantum Physics throws in our way. Again, when dealing with the limits of human knowledge, it is quite essential to stick to the obvious, before delving, if briefly, into the inexplicable. Without a sturdy grasp of what we do know, we are prone to misjudge the unknown, and indeed the obvious limits of the knowable. We none of us like to admit the shortcomings of our own knowledge-but, if they are there, which they are, it makes sense 
to "own" them-this is not only more sensible, but healthier.

To explore what Quantum Physics consists of, the best approach is to follow what the pioneers actually said. By including verbatim excerpts from, say, Nobel Prizewinners, then the real underlying issues become clearer. To this end, contributions from Richard Feynman are explored elsewhere (Johnson, 2017a) and those by Leon Lederman, here.

Much, if not most of science consists of measuring, counting, and sorting by numbers. This is obvious in the macro-world, but becomes problematic to impossible in the micro. Lederman shows this most clearly. "We don't change the temperature of a lake, say, by dipping a small thermometer into it. But dipping a fat thermometer into a thimble of water would be stupid, since the [heat in the] thermometer would change the temperature of the water. In atomic systems, quantum theory says, we must include the measurement as part of the system." (Lederman, 1993).

It is important to remember that we think in the large. We reason by comparing what we see with what we expect. If we cannot see something clearly, then our reasoning suffers from imperfect foundations. Human ingenuity has by-passed the limits of our visual acuity in utterly astonishing ways-and we continue to do so. Especially impressive were the "bubble-chambers" which magnified "invisible" particles by coaxing them to leave a string of bubbles, which we could well see, to show what had happened to items that we never will.

What this confirms is that ultimately we have to have photons hitting our retinas to see anything. Lederman's description relates to heat, but the same restrictions apply to every item on the nano scale. Bouncing one photon against another, which we would need to do to see it, must, inexorably, dislodge it. Of course there are ways around this, ingenuity is formidable, but the limitations that remain must be acknowledged.

Carlo Rovelli was among the first to state this openly. He tells us that science has collapsed and he puts the matter most succinctly. "Facile nineteenth-century certainties about science-in particular the glorification of science understood as definitive knowledge of the world-have collapsed. One of the forces responsible for their dismissal has been the twentieth-century revolution in physics, which led to the discovery that NEWTONIAN PHYSICS, despite its immense effectiveness, IS ACTUALLY WRONG, in a precise sense. Much of the subsequent philosophy of science can be read as an attempt to come to grips with this disillusionment. What is scientific knowledge if it can be wrong even when it is extremely effective?" (Rovelli, 2011, emphases added)

Few will readily accept the notion that "Newtonian physics... is actually wrong". Even the addition of the rider "in a precise sense" is unlikely to ensure the point remains intact. Yet there is irrefutable scientific evidence that the world out there is not what we might reasonably have expected. And if the discussion extends to include healthcare, then knowledge takes on an additional weight-by entertaining obsolete dogmas, old-style world-views or suchlike, there is then nothing to stop the equivalent of blood-lettings and ducking-stools 
re-emerging in short order, something that, for those robust enough to observe it, has already happened.

And yet, despite these grave handicaps, humanity has made enormous strides. Healthcare for one, is vastly more successful in recent centuries than it was earlier (today's psychiatry being the glaring, pathognomonic exception). We still unemotionally contemplate a thermonuclear holocaust, which is the gravest health problem of them all, nevertheless there is a clear way through, that does give an element of stability, a modicum of security, despite the Uncertainty which our Quantum researchers have irretrievably established.

\section{Kant's Dogmatic Slumbers}

"I freely admit", said Kant in 1781, "that it was David Hume's remark that first, many years ago, interrupted my dogmatic slumber" (Kant, 1781). The "spark" to which he referred was Hume's incendiary notion that though we might reasonably expect Causality to work most of the time-there can never be any guarantee that it would, certainly never a scientific guarantee. An event may well follow a cause today, but there is no necessity for it to do so tomorrow. In other words, reason as we might, the fact that we conclude that B follows A today, affords this reasoning no CERTAINTY that it will do so again. There is only a given probability that it will, and that's all there has ever been since 1739 .

The parallel with the Uncertainty Principle is stark. At the heart of our logic, our cognition, is precisely the same element of Uncertainty that emerges from a dispassionate exploration of subatomic physics. Hume's acclaim sank, and Kant lost himself in conundrums-neither widened their philosophy to include healthcare-happily by doing so, we can point up an escape route that's been followed for millennia, well before Hippocrates.

Not everyone will welcome scientific proof that Hume was right, and Kant's answer to him, wrong-but since science currently dominates, it's important to drive the parallel home. Thus Lederman again, while discussing the double slit enigma, (also described in more detail elsewhere (Johnson, 2017a)) actually names the crisis as one of logic. The experiment he refers to involves shining photons or electrons through first one narrow slit then two, first as a beam, then singly, one a minute. The results are not what one would reasonably have expected. "However, where the particle [in the single electron experiment] lands depends on whether one or two slits are open. So a [single] particle going through slit one, seems to know whether slit two is open or closed, because it appears to change its path depending on that information... Since particles can't "know", a wave-particle ambiguity has created a logical crisis. (Lederman, op cit p. 178)

Here is science actively confusing our attempts at reasoning. Here is scientific justification for including the word "probably" in every statement, bar none. But there's worse. According to Lederman, "In classical science we stress the importance of replicating experiments. In the quantum world, we can replicate eve- 
rything except the result." (op cit p 180) Again, placing this in the context of healthcare, gives it a bite generally lacking from orthodox philosophical discourse. "We gave this drug to 1000 other people, but we have no expectation that your results will replicate theirs". How many would tolerate this for their own personal healthcare?

Of course, there are those who are happy to discount all physics, to maintain that somehow our macro world of cells, tissues and physiology bears no direct relationship to these inexplicabilities in our subatomic foundations. Even Einstein himself, physics giant though he was, strove to preserve just such a separation. Lederman comments on this as follows. "Bohr's defence was that the incompleteness that worried Einstein was not a fault of the theory but a quality of the world in which we live... This subjectivity challenges our cherished beliefs in cause and effect. If an electron starts at point $A$ and is seen to arrive at point $B$, it seems "natural" to assume it took a particular path from $A$ to $B$. Quantum theory denies this, saying that the path is unknowable. All paths are possible, and each has its probability". (op cit p 186)

Dogma can be defined as sticking to earlier views, despite copious evidence to the contrary. It is a standard human story-the initiator asserts that those who have climbed to the top of the tree, need to confess it's the wrong tree-human nature recants only grudgingly.

And the central dogma that needs to fade is that we live in a Clock Work Universe-subatomic physics proves we don't. At least it does for those willing to hear. Put simply, the scientific myth is that we need only find all the cogs, levers and springs, and then we can happily ditch subjectivity forever. Electrons and their ilk betray this simplistic notion, except for those for whom simplicity is more important than evidence or realism. However, discuss this in a healthcare setting, and even the latter might concede.

Somehow health deflects and generally defeats the Uncertainties of its collective subatomic parts. Living skin heals, where dead skin does not. There is not now, nor ever will be any sensible coherent explanation for this, scientific or otherwise. But there is a vital need to exploit it, nevertheless. There is something about living processes that defies the Second Law of Thermodynamics-i.e. entropy. This is explored further elsewhere (Johnson, 2017b).

Here we may co-opt and expand the term "intent", well established in legal circles, generally taboo in science, politics and economics, and disastrously absent in today's psychiatry. "Intent" means we direct the flow of thought, or in this context, the flow of electrons. How we do this, is forever unknowable, but that we do, needs asserting against considerable opposition-indeed, for healthcare to flourish, especially mental healthcare, it is essential, or more to the point, it's vital.

Again, this point has been made before, notably in Samuel Johnson's brilliant aphorism, from 1778, "All Theory is against the Freedom of the Will; all EXperience for it'. What this paper proposes is that since no Theory can now ever be $100 \%$ Certain, ever again, we need wider evidence to impact on the question. 
Thus the Experience offered here is healthcare. In clinical experience, the very term appears "in clear"- "healing by first intention" was well established in the pre-antibiotic era, referring to skin closure with less infection, something we may need again before too long.

The notion of "intent" again must carry an inevitable limitation-the word "probably" needs inserting here too. The "cloud" that characterises the electron itself, its Uncertainty, is faithfully mirrored in every single word we ever usenone can ever be $100 \%$ exact either, all need a helping hand to fill in the inevitable verbal lacunae. The puzzle is that somehow, despite all this shapelessness, the electrons in our cerebral tissue do obey our summons from time to time, not all the time, but enough to make a difference. A parallel can be found in plants, with which we share a common ancestor of perhaps a billion years ago-in photosynthesis Quantum Uncertainty is also corralled, in their case capturing solar energy, without which we wouldn't be, we'd starve.

\section{The Trauma Still Hurts}

Healthcare too floats on an unknowability, just as insecurely as any subatomic wave-particle, but, happily for us, there's a radical difference. Whereas electrons and their ilk buzz continuously about, living cells organise, they "gather" themselves, they resist entropy. In a nutshell, living skin heals, where dead skin does not. If you want your skin cuts to heal, ensure that the surrounding tissue remains alive long enough to do so.

This radical, nay vital difference between living processes and dead or inanimate ones, is rarely given the prominence it deserves. It is not a matter of personal belief, nor of anyone's subjective opinion-it's just that healthcare could not continue, unless living organisms, notably human beings, exhibited this indefinable difference between animate and inanimate. Expanding the notion of "intent" seems the most apt label to convey this vital characteristic. Elsewhere, as mentioned, I discuss how this process, unlike any other, combats the Second Law of Thermodynamics by actively undoing entropy or disorganisation (Johnson, 2017b), "anti-entropy" then contracts to "antropy".

Far from being some sort of mechanical contrivance, such as a digital computer, human consciousness partakes directly of this "living component", this expanded "intent". Indeed, not only does this indefinable animate element allow "clock-work" computers to be programmed, it enabled their invention in the first place. The notion that so called Artificial Intelligence could one day dominate our world overlooks the fact that computers can never do more than they are programmed to do, so if this unfortunate catastrophe occurred, it would be because they have been programmed, deliberately (i.e. "intentionally") or otherwise, to do so. A coherent account of consciousness is given elsewhere (Johnson, 2016a). Talk of the "semantic" web, or Web 3.0, will peter out, unless the link between meaning and "intent" is made clear-once it is, than the digitisation of say, the medical record, becomes feasible (Johnson, 1980). Those clinging to the 
notion of a Clock Work Universe should peer into the bowels of an unprogrammed digital computer-clockwork, yes-boring, for sure-only "intent" enlivens it, literally.

Deploying the term "intent" as the most straightforward verbal label for this indefinable animate process, links this point to wider considerations. As mentioned, "intent" finds an indelible place in law- "when you picked up that spade, did you "intend" to dig or to kill?" Despite linguistic handicaps in practice, there is simply no prospect of it ever being omitted from legal considerations. Sadly the same cannot be said either for science in general, nor economics, nor, worst of all, for psychiatric healthcare.

On the assumption that we do not live in a Clock Work Universe, that human beings can realistically exercise "intent", not always, not everytime, but enough to make a difference, then the whole of mental illhealth can be placed in a far clearer context than usual. Thus, putting "intent" firmly centre stage provides us with a splendidly obvious working definition-“if your mind won't let you do what you want (what you "intend"), then find out the bits that get in the way, and zap them."

Of course this option simply doesn't arise if psychiatry insists that doctors treat only the brain, and ignore the mind, which today's psychiatry has done since 1980, a point discussed more fully elsewhere (Johnson, 2016b). Here, if nowhere else, is the scientific evidence that "intent" is vital for healthcare. If today's psychiatry were once to give due weight to the available objective scientific evidence, radical change would be mandatory. Clear data already shows that those taking prescribed medication, compared with those who do not, suffer worse over a 20 year period by a margin of $68 \%$ to $8 \%$. Given this discrepancy, how can radical and urgent reform be by-passed? No other branch of medicine could tolerate such a gross known discrepancy in clinical outcomes (Harrow, 2014). Worse, when the Harvard Centre for Ethics, no less, lays out a succinct, undeniable case of institutional corruption (Whitaker \& Cosgrove, 2015), any other profession would surely pause for thought. Not so today's psychiatry, which sails on oblivious, an entirely unjustifiable and damaging medical solipsism.

A useful metaphor is to suggest that "intent" can shuffle bits of one's mental furniture around-this is what our expanded neocortex is for, modelling our surroundings, especially our social networks, so as to anticipate problems, and seek their solution. On the assumption that "intent" can do this, again not everytime, but that that is what it is for-then when the mind goes wrong, there is a simple remedy, obvious to all. Simple, but by no means easy.

Here we need to deploy recent advances in the impact of trauma/terror. Early brain scans show that when audio tapes of a traumatic event are played, the sufferer's frontal lobes and speech centre, go "off line" (Van der Kolk, 2016). It's as if the person were suffering a stroke. With disabled frontal lobes, cognition is stifled, and, as with so many sufferers from childhood traumas, the pain, the torture, the hurt, can continue unabated, since it cannot be "thought" about at all, 
so cannot be removed, despite the intervening decades.

\section{Why "Dynamic" Security Works Best}

Which brings us to what "intent" is for, at least in healthcare. Throughout the biosphere, animate organisms constantly check their surroundings with the "intent" or purpose of taking evading action-when it gets too hot, or too dry, (or too uncomfortable,) they move or grow or adapt (as we ourselves do, every minute) - only when they die, does this ability to respond, this capacity for "intent", this responding-ability, cease. The corollary is that those who fail to respond, risk shortened longevity, if not extinction. This is the Iron Law of Evolutionadapt or perish. It applies universally. It has no exceptions, not even ourselves. There is no Uncertainty about this one, as the Dodo demonstrated, and we might be about to.

So if we use our "intent" to survive longer, or, put another way, to retain our health-how come so many continue to sufferer from a threat which no longer applies? Damage that existed many decades years ago, but now does not. It is no longer here, in today's reality. It ceased. Except clearly, it has not stopped in the mind, where it festers.

As a child, the sufferer could find no resolution to, nor rescue from the damage and pain being inflicted on him or her then. In the decades since, s/he has continued to be unable to do so-the same pain has remained as before. It is hard to avoid the conclusion that s/he has decided, deep down, that no resolution nor remedy is ever going to be possible-a point with which today's psychiatry agrees.

Building on van der Kolk's insight (loc cit) that the impact of trauma is like having a stroke, why not implement an analogous "physiotherapy"? With the more orthodox neurological damage, enthusiasm, encouragement and vigorous consensual exercises can restore astonishing degrees of recovery. The same principle applies to these frontal lobe "strokes". Taking active steps to re-energise both the frontal lobes and the speech centre, may initially face a sufferer's active resistance, as is common enough with physical physiotherapy, and for the same reasons. But over time, and with steady patience, it can also restore cerebral circulation, with total abolition of the obsolete trauma that only remained because it could not be thought about.

Calling this "verbal physiotherapy" allows a marked contrast with psycho-therapy-thereby promoting something that is immediately obvious, uncontroversial, open to all, and universally desirable. The process may be linked with the foregoing, by describing it as empowering "intent". Alternatively it can be seen as "replacing "social defeat" with "social delight"-for all." Indeed, SOCIAL DEFEAT is the only pragmatic psychiatric diagnosis we will ever need medically, since it covers the full range of psychiatric disorders, and holds out a positive, obvious, and humane remedy for all.

Here "intent" in the mental sphere partakes of the characteristics of healing 
elsewhere. When cut skin heals, the various skin cells cooperate to close the gap-they cannot do so, if they are dead or lack sufficient blood supplyidentical reasoning applies to terror-induced frontal lobe ischaemia, and the results can be even more gratifying, whether for so called psychopathy, psychotic symptoms, or worse. Social defeat is so easy to understand, so easy to see where it comes from, and is an open therapeutic goal for even the most untrained.

"Intent" is closely related to consent-which is where "dynamic" security blossoms. The key to civilised social relations is ensuring fully informed consent. "Dynamic" security does not rely on bolts and bars, and other human-devised contraptions-it turns the situation on its head, and seeks agreement, seeks consent, seeks civilised outcomes. This even works in the depths of a maximum security prison wing, where working with 60 murderers enabled this approach to be honed in practice.

It did take me some time to build up my confidence, before I was able to directly enlist these murderers' "intent'. Eventually I learned to give them a warning- "if you frighten me, I cannot help you". A radical departure, and quite a turning point. These violent prisoners had attempted to escape their earlier problems of insecurity by killing, or threatening to kill, much as our nation states do today. In 1991-6, I was consultant psychiatrist for a Special Prison Unit for violent, unstable, lifers, who taught me a great deal (BBCtv, 1997). I worked on the assumption that since the human species relies on being sociable to avoid extinction, there was, underneath their violent exteriors, a sensible mature individual. I invited them to rid themselves of their appalling childhoods-not to exonerate or excuse their horrendous behaviours, but to prevent it happening again, especially not to me.

The key was trust-they needed to believe that though I was at least as powerful as their torturer (so as not to be similarly overwhelmed by him or her), I could nevertheless be trusted not to hurt them. Had I been weaker, I'd have been dismissed, or worse. And crucially I needed confidence that there was a chance they would respond positively to my warning, which they would only do if my offer of help was believable, since they then stood to lose something by frightening me. This strategy is available to be implemented on a global scale.

Here I was deploying two factors-one, that each individual did indeed have an element of "intent", a capacity deep inside to empathise, to socialise, to cogitate and indeed to change, however well hidden this had previously been. Two, that by persuading them to talk, to undergo various verbal exercises with consent ("verbal physiotherapy"), that this would enable their frontal lobes and speech centres to be re-activated. More, once this re-activation had started, that a civilised, non-violent, sociable, responsible individual would emerge. They responded. For three years, no alarm bells were rung in that maximum security prison wing, down from 20 a year in the previous seven. I took this to be objective scientific evidence that unpacking trauma in this way, could indeed increase social delight, not that I expressed it directly in those terms at the time, but neither did the prevailing prison authorities, either then nor since. A magnificent 
description of how this process works in practice, together with a searing account of its antecedents, is provided in a recent book by Erwin James (James, 2016). Though my work played no part in the proceedings he describes so deftly, it is striking that the notion of being born "lovable" appears as the turning point both for him, and for those I treated in my unit.

Healthcare is generally thought of as applying to individuals, what you or I should do to ensure our own health. However, the biggest health threat of them all, is nuclear war, which a recent edition of that authoritative journal, The Economist, judged "could happen" (The Economist, 2017). Whether the differences between animate and inanimate are of the order described here, there can be no dispute that radioactivity is toxic to the former, of whatever nature or species. A deliberate collective government policy that entails flooding our one and only biosphere with long-term radioactivity represents a direct challenge to health, for all.

That such a policy can even be seriously entertained speaks ill of our joint ability to think. It points to rather more frontal lobe "blockage" than it's generally comfortable to contemplate. Climate change seems set to desertify much of our existing arable land, and to flood our many costal megapolises-but this threat, also man-made, is peanuts compared with thermonuclear irradiation. Must our forthcoming era of abundance drown prematurely, solely because of our unthinking intemperance.

So what would be the global equivalent of my above warning to the murderers? How would "dynamic" security apply worldwide? Well there are several assumptions which need wider acceptance- "intent" being only the first. The notion that all humans are intrinsically sociable took a heavy battering in 1914, from which we have yet to recover. Can we recover soon enough? Clinically, war (and violence) originates in kindergartens, and is an expensive way of making things worse (as is all violence)—only maturing "intent", heals it.

\section{Final Prognosis}

Here's a global healthcare prescription. For the price of two stealth bombers, 25 million North Korean citizens could be paid a regular yearly income. Their economic insecurity would vanish. Supplying them with a living allowance, white goods such as solar powered washing machines, desalinators, unlimited webinars, along with indispensible trustworthy support-all this would mobilise their "intent" to implement regime change. Doing so would be a vastly cheaper alternative to any variant of war.

In healthcare terms we were happy to immunise the global community against small pox; we cooperated to eliminate a disease which killed many people. Why not implement a similar global campaign to immunise against, and so avert violence, which kills more. The challenge, as above, is to find an agreed, realistic, scientific, objective basis for amending "I'll probably be there for you", so that it becomes a healthier-"your peace-of-mind relies on you being certain of me". 
In our global society, your certainty, your feeling of security, and your peaceof-mind impinge on mine, and vice versa.

Grounds for optimism? Yes certainly, but a favourable prognosis is clinically unlikely, unless-1) "dynamic" security displaces the current kindergarten variety worldwide, 2) frontal lobes are re-energised universally, via truth in social and other media, and 3) both these are implemented soon enough. Science fact-we live (and die) only once.

\section{References}

BBCtv (1997). Predators. TX. 3/3/97.

http://news.bbc.co.uk/hi/english/static/audio_video/programmes/panorama/transcript s/transcript_03_03_97.txt

Harrow, M., Jobe, T. H., \& Faull, R. N. (2014). Does Treatment of Schizophrenia with Antipsychotic Medications Eliminate or Reduce Psychosis? A 20-Year Multi-Follow-Up Study. Psychological Medicine, 1-10.

James, E. (2016). Redeemable: A Memoir of Darkness and Hope (p. 284). Bloomsbury Publishing.

Johnson, B. (2016a). Chapter: Consciousness: Using Clinical Evidence To Link Consciousness With Its Twin Perils Of Psychosis and Violence. In L. Alvarado (Ed.), Consciousness: Social Perspectives, Psychological Approaches \& Current Research. Nova Science Publishers, Inc.

https://www.novapublishers.com/catalog/product_info.php?products_id=60019

Johnson, B. (2016b). Why PSYCHIATRISTS Need Your Help-Now:-(. https://medium.com/@BobTrustConsent/why-psychiatrists-need-your-help-now-f83a4 ca82a68

Johnson, B. (2017a). Richard FEYNMAN-A Quantum Genius Who Helps Drown PSYCHIATRY - You Can Be Neither Healthy Nor Sane in a Clockwork Universe. https://medium.com/@BobTrustConsent/richard-feynman-a-quantum-genius-who-hel ps-drown-psychiatry-you-can-be-neither-healthy-nor-sane-a0db12097f2f

Johnson, B. (2017b). How EINSTEIN Hampered HEALTHCARE, Both Medical and Societal.

https://medium.com/@BobTrustConsent/how-einstein-hampered-healthcare-both-me dical-and-societal-d29cd129be9a

Johnson, R. A. (Bob) (1980). Real Time Retrieval of Clinical Data. Ph.D. Thesis. UK: UMIST.

Kant, I. (1781). Prolegomena to Any Future Metaphysic That Will Be Able to Present Itself as a Science. Manchester University Press, Trans Lucas, 1953, 9.

Lederman, L. (1993). The God Particle: If the Universe Is the Answer, What Is the Question? (p. 176). NY: Houghton Mifflin Company.

https://doi.org/10.1063/1.2808974

Rovelli, C. (2011). The First Scientist: Anaximander and His Legacy. Westholme Publishing.

The Economist (2017). It Could Happen. 5 August 2017. 9.

Van der Kolk, B. (2016). The Body Keeps the Score: Mind, Brain and Body in the Transformation of Trauma (pp. 63, 176). Penguin.

Whitaker, R. (Author), Cosgrove, L. (Contributor) (2015). Psychiatry under the Influence: Institutional Corruption, Social Injury, and Prescriptions for Reform. Paperback Palgrave Macmillan. 